\title{
Avaliação ergonômica do processo de mensuração florestal
}

\author{
Ergonomic evaluation of forest mensuration process
}

\author{
Stanley Schettino1, Luciano José Minette², \\ Agostinho Lopes Souza ${ }^{3}$ e Amaury Paulo Souza ${ }^{3}$
}

\begin{abstract}
Resumo
Este estudo realizou uma avaliação ergonômica dos trabalhadores em oito atividades de mensuração florestal, no Estado de Minas Gerais. Foi avaliado, para cada uma das atividades desenvolvidas, a carga de trabalho físico, a biomecânica, o risco de LER/DORT e os fatores ambientais ruído, vibração e conforto térmico, de forma a determinar os riscos ergonômicos a que os trabalhadores estavam expostos durante o desenvolvimento dessas atividades. Os resultados evidenciaram que o ambiente de trabalho estudado proporcionava diferentes riscos ergonômicos aos trabalhadores. Na avaliação da carga de trabalho físico, apenas as atividades de determinação do fator de empilhamento e o inventário físico de madeira encontraram-se dentro dos limites de carga cardiovascular recomendados. A análise biomecânica indicou que a cubagem rigorosa e a coleta de discos de madeira ultrapassaram a carga limite recomendada. As atividades de cubagem rigorosa e a coleta de solos foram consideradas como de altíssimo risco para o desenvolvimento de LER/DORT. A sobrecarga térmica foi o fator ambiental que apresentou maior risco ergonômico aos trabalhadores em todas as atividades, seguido do ruído nas atividades de cubagem rigorosa e coleta de discos de madeira.
\end{abstract}

Palavras-chave: Manejo florestal; Risco ergonômico; Saúde do trabalhador.

\begin{abstract}
This study carried out an ergonomic evaluation of workers in eight forest mensuration activities in the State of Minas Gerais. For each of the activities developed, the physical workload, the biomechanics, the risk of RSI / MSDs and environmental factors noise, vibration and thermal comfort, in order to determine the ergonomic risks to which workers were exposed during the development of these activities were evaluated. The results showed that the studied workplace provides different ergonomic risks to workers. In evaluating the physical workload, only the activities of the stacking factor determination and the wood physical inventory were within the recommended cardiovascular load limits. Biomechanical analysis indicated that the rigorous volume determination and collecting wooden disks exceeded the recommended load limit. The activities of rigorous volume determination and soil collecting have been considered as with great risk of developing RSI / MSDs. The thermal overload was the environmental factor that presented greatest ergonomic risk to workers in all activities, followed by the noise in the activities of rigorous volume determination and collecting wooden disks.
\end{abstract}

Keywords: Forest management; Ergonomic risk; Worker's health.

\section{INTRODUÇÃO}

A preocupação com o planejamento, ordenamento e o uso da madeira, cada vez mais exige uma maior precisão na quantificação do volume dos povoamentos florestais (MIGUEL et al., 2010), no conhecimento dos fatores associados a produção (solos, clima, idade, taxa de crescimento, dentre outros) e da qualidade intrínseca dos produtos a serem produzidos, tais como densidade básica e teores de celulose, lignina e carbono fixo, dentre outros (ABRUZZI, et al., 2012; BRAZ et al., 2014). Ainda, as atividades de mensuração florestal podem auxiliar na avaliação e monitoramento da biodiversidade (CORONA et al., 2011), bem como na avaliação de estoques de carbono (MOHREN et al, 2012).

\footnotetext{
${ }^{1}$ Doutorando em Ciência Florestal. UFV - Universidade Federal de Viçosa. Campus Universitário - 36570000 - Viçosa, MG, Brasil. E-mail: stanley.schettino@oi.com.br.

2Professor Associado do Departamento de Engenharia Elétrica de Produção. UFV - Universidade Federal de Viçosa - Campus Universitário - 36571000 - Viçosa, MG, Brasil. E-mail: minette@ufv.br.

3Professor titular do Departamento de Engenharia Florestal. UFV - Universidade Federal de Viçosa. Campus Universitário - 36571000 - Viçosa, MG, Brasil. E-mail: alsouza@ufv.br; amaury@ufv.br.
} 
Nas atividades de mensuração florestal é cada vez mais comum a utilização de equipamentos eletrônicos, tais como: suta eletrônica, coletores de dados e medidores de altura. Isto se deve ao fato de que esses equipamentos facilitam a coleta de dados, bem como a posterior manipulação dos mesmos (FREITAS; WICHERT, 1998). Mesmo assim, o manuseio de todos esses equipamentos é realizado de forma manual e, ainda, em algumas atividades, torna-se necessário o uso de ferramentas manuais. De acordo com Vibrans (2010), o rendimento das equipes de campo é influenciado por uma série de fatores, entre condições meteorológicas e de acesso, topografia do local e densidade da vegetação do sub-bosque. Nessas condições, tais atividades apresentam elevado dispêndio energético, repetitividade e posturas forçadas, além da possibilidade do desenvolvimento de distúrbios osteomusculares (FIEDLER et al., 2011; OJHA; KWATRA, 2011).

Os efeitos do acúmulo da fadiga devido à sobrecarga do trabalho podem contribuir para a ocorrência de diversos problemas, dentre eles, os distúrbios relacionados à saúde mental e psicossomáticos (SATO, 2002). Além dos prejuízos para os indivíduos, a fadiga também pode trazer consequências econômicas, tais como maiores índices de absenteísmos e de acidentes de trabalho, aposentadoria por invalidez, perda da capacidade para o trabalho, diminuição da eficiência (VAREKAMP; VAN DIJK, 2010) e, consequentemente, queda nos índices de qualidade e produtividade.

Diante deste cenário, os estudos ergonômicos buscam harmonizar o sistema de trabalho adaptando-o ao ser humano, através da análise da tarefa, da postura e dos movimentos do trabalhador, assim como de suas exigências físicas e psicológicas, objetivando reduzir a fadiga e o estresse, proporcionando um local de trabalho confortável, seguro e consequentemente aumentando a eficiência e o rendimento das atividades baseados em normas, regulamentos e certificados.

Através da avaliação ergonômica dos postos de trabalho das atividades de mensuração florestal, com a determinação carga de trabalho físico, das avaliações biomecânica, do risco de LER/DORT e do ambiente de trabalho, este estudo teve como objetivo determinar os riscos ergonômicos a que os trabalhadores estavam expostos durante o desenvolvimento dessas atividades.

\section{MATERIAL E MÉTODOS}

\section{Caracterização da amostragem}

Os dados foram coletados em áreas de uma empresa florestal localizadas nas regiões do Jequitinhonha/Mucuri e do Médio Vale do Rio Doce, Estado de Minas Gerais, situadas entre os meridianos de $42^{\circ} 17^{\prime} 00^{\prime \prime}$ a $43^{\circ} 25^{\prime} 00^{\prime \prime}$ longitude a oeste de Greenwich e os paralelos de $17^{\circ} 05^{\prime} 00^{\prime \prime}$ a $18^{\circ} 50^{\prime} 30^{\prime \prime}$ latitude a sul da linha do Equador, com altitude média de 800 metros. Segundo a classificação climática de Köppen, o clima predominante na região é Aw - tropical chuvoso de savana, ou seja, inverno seco e chuvas máximas no verão, sendo que a estação chuvosa ocorre entre os meses de outubro e março. A precipitação pluviométrica média anual é de $1.300 \mathrm{~mm}$. O solo da região é classificado como Latossolo Vermelho-amarelo álico, a textura é argilosa e a topografia varia de suave ondulada a ondulada (TONELLO et al., 2006). Os levantamentos de campo foram realizados no mês de fevereiro de 2015, o qual apresentou temperaturas média, máxima e mínima de 26,5, 32,5 e $20,5^{\circ} \mathrm{C}$ respectivamente.

A amostra foi constituída por 24 (vinte e quatro) trabalhadores, totalizando 100,0\% da população que exercia as atividades de mensuração florestal na empresa amostrada, os quais apresentaram idade variando de 20 a 52 anos, com média de 35 anos, massa corporal entre 54,3 e 89,8 kg, com média de 72,5 kg e estatura desde 1,59 até 1,85 m, apresentando média de 1,65 m. Todos os trabalhadores foram informados sobre os objetivos e a metodologia do trabalho, tendo assinado o Termo de Consentimento Livre e Esclarecido estando, portanto, em conformidade com a Resolução n ${ }^{\circ}$ 196/1996 da Comissão de Ética em Pesquisa do Ministério da Saúde.

As atividades florestais analisadas encontram-se caracterizadas na Tabela 1. 
Tabela 1. Descrição das atividades de mensuração florestal analisadas.

Table 1. Description of forest mensuration activities analyzed.

\begin{tabular}{|c|c|}
\hline Atividades & Caracterização da atividade \\
\hline $\begin{array}{l}\text { Levantamento de campo } \\
\text { para Inventário Florestal } \\
\text { (Contínuo e Pré-Corte) - } \\
\text { Medição de Parcelas }\end{array}$ & $\begin{array}{l}\text { No interior das áreas de florestas plantadas (sob o dossel das mesmas), em áreas com } \\
\text { declividade variando de zero a } 45^{\circ} \text {, com ou sem presença de sub-bosque. Consiste no } \\
\text { deslocamento a pé para a instalação de unidades amostrais (parcelas) e medição de } \\
\text { variáveis das árvores (diâmetro e altura). Para a instalação e demarcação das parce- } \\
\text { las, são utilizados trena, facão e tinta. Para a medição das variáveis são utilizados suta } \\
\text { (pesando } 0,4 \mathrm{Kg} \text { ) ou fita métrica para medição dos diâmetros e clinômetro para medi- } \\
\text { ção das alturas. Os dados coletados são anotados em coletores de dados eletrônicos. }\end{array}$ \\
\hline $\begin{array}{l}\text { Levantamento de s } \\
\text { obrevivência (Pós-Plantio } \\
\text { e de Regeneração) }\end{array}$ & $\begin{array}{l}\text { Em áreas recém-plantadas ou áreas recém colhidas, respectivamente (num prazo má- } \\
\text { ximo de até seis meses após o plantio ou a colheita), consiste na demarcação de par- } \\
\text { celas amostrais para a contagem de mudas vivas. Deslocando-se a pé no interior dos } \\
\text { talhões, a céu aberto, utiliza-se facão, trena e coletor de dados eletrônico. }\end{array}$ \\
\hline Coleta de solos & $\begin{array}{l}\text { Consiste na coleta de amostra de solos utilizando trado (pesando } 3,1 \mathrm{~kg} \text { ), balde (com } \\
\text { até } 2,0 \mathrm{~kg} \text { de solo, quando cheio), enxadão, uma ferramenta específica para coleta de } \\
\text { discos de solos (pesando } 4,9 \mathrm{Kg} \text { ) e penetrômetro. Deslocamento a pé, sob o dossel } \\
\text { das florestas plantadas, em declividades variáveis de zero até } 45^{\circ} \text {. Ao final do proces- } \\
\text { so, as amostras são depositadas em sacolas plásticas, identificadas e armazenadas } \\
\text { no veículo de apoio. }\end{array}$ \\
\hline $\begin{array}{l}\text { Coleta de discos } \\
\text { de madeira }\end{array}$ & $\begin{array}{l}\text { Consiste na derrubada de árvores e coleta de amostras, discos de seções dos fustes } \\
\text { das árvores, para determinações laboratoriais diversas. É realizada no interior das } \\
\text { florestas plantadas, sob o dossel, utilizando motosserra (pesando } 5,6 \mathrm{~kg} \text { ), trena e suta. } \\
\text { Deslocamento a pé em declividades variáveis desde zero até } 45^{\circ} \text {. Ao final do proces- } \\
\text { so, os discos coletados são identificados e armazenados em sacolas plásticas, sendo } \\
\text { transportadas até o veículo de apoio, podendo chegar a até } 5,0 \mathrm{~kg} \text { de amostras. }\end{array}$ \\
\hline $\begin{array}{l}\text { Cubagem rigorosa } \\
\text { de árvores }\end{array}$ & $\begin{array}{l}\text { Consiste na derrubada de árvores e medição de variáveis ao longo dos fustes (com- } \\
\text { primento e diâmetro). É realizada no interior das florestas plantadas, sob o dossel, } \\
\text { utilizando motosserra (peso aproximado de } 7,0 \mathrm{~kg} \text { ), trena e suta. Deslocamento a pé } \\
\text { em declividades variáveis desde zero até } 45^{\circ} \text {. Os dados coletados são armazenados } \\
\text { em coletores eletrônicos. }\end{array}$ \\
\hline $\begin{array}{l}\text { Determinação de } \\
\text { fator de empilhamento }\end{array}$ & $\begin{array}{l}\text { Após a medição das cargas de madeira nos caminhões (comprimento das toras e al- } \\
\text { tura das pilhas), a carga é depositada em separado, quando são medidos, tora a tora, } \\
\text { os diâmetros nas duas pontas e o comprimento. Trabalho a céu aberto, nas posições } \\
\text { de pé e agachado, utilizando régua graduada de alumínio (pesando } 0,5 \mathrm{~kg} \text { ), trena e } \\
\text { suta ou fita métrica. Os dados coletados são armazenados em coletores eletrônicos. }\end{array}$ \\
\hline $\begin{array}{l}\text { Inventário físico } \\
\text { de madeira }\end{array}$ & $\begin{array}{l}\text { Medição dos volumes de madeira armazenados em pilhas nos pátios ou na margem } \\
\text { dos talhões. Trata-se de atividade realizada a céu aberto, sempre em pé ou agachado, } \\
\text { utilizando régua de madeira graduada (pesando } 1,6 \mathrm{~kg} \text { ) e trena. Os dados são digita- } \\
\text { dos e armazenados em coletores. }\end{array}$ \\
\hline $\begin{array}{l}\text { Levantamento residual } \\
\text { pós-colheita }\end{array}$ & $\begin{array}{l}\text { Consiste na determinação de perdas de madeira após as atividades de colheita, bal- } \\
\text { deio e transporte de madeira de uma determinada área. A partir da demarcação de } \\
\text { parcelas amostrais, são medidos o diâmetro (nas duas pontas) e o comprimento de } \\
\text { todas as peças de madeira com diâmetro maior que um valor mínimo pré-determinado. } \\
\text { A atividade é realizada a céu aberto, nas posições de pé e agachado, utilizando facão, } \\
\text { trena, suta ou fita métrica, além de coletor de dados. }\end{array}$ \\
\hline
\end{tabular}

\section{Avaliação da Carga de Trabalho Físico}

A carga de trabalho físico foi avaliada por intermédio do levantamento da frequência cardíaca dos trabalhadores durante a realização de cada atividade analisada. Os dados foram coletados e analisados por meio do monitor cardíaco portátil marca GARMIN, modelo Forerunner 310XT, formado por um receptor digital de pulso, uma correia elástica e um transmissor de dados com eletrodos. O transmissor fixado ao trabalhador na altura do tórax, por meio de correia elástica, emite os sinais de frequência, que são captados e armazenados pelo receptor de pulso em intervalos de cinco segundos.

A carga máxima de trabalho foi avaliada utilizando-se os dados de frequência cardíaca, por meio dos quais foram calculados os valores médios dos diferentes períodos de trabalho, analisando as curvas e, particularmente, os picos de frequência cardíaca. A carga cardiovascular corresponde à porcentagem da frequência cardíaca do trabalho, em relação à frequência cardíaca máxima utilizável. De acordo com Apud (1989), a carga cardiovascular do trabalhador em jornada de 8 horas não deve ultrapassar $40 \%$ da frequência cardíaca do trabalho. A carga cardiovascular e os tempos de descanso são determinados utilizando-se as Equações 1, 2 e 3 a seguir: 
Schettino et al. - Avaliação ergonômica do processe de mensuração florestal

$$
\begin{gathered}
C C V=((F C T-F C R) /(F C M-F C R)) \times 100 \\
F C L=0,40 \times(F C M-F C R)+F C R \\
T r=(H t x(F C T-F C L)) /(F C T-F C R)
\end{gathered}
$$

em que:

$\mathrm{CCV}$ = carga cardiovascular, em \%;

FCT = frequência cardíaca média de trabalho;

FCM = frequência cardíaca máxima (220 - idade);

FCR = frequência cardíaca de repouso;

$\mathrm{FCL}$ = frequência cardíaca limite;

$\mathrm{Tr}$ = tempo de repouso, descanso ou pausas, em minutos; $\mathrm{e}$

$\mathrm{Ht}=$ duração do trabalho, em minutos.

Todos os cálculos foram realizados considerando as médias após obtidos os cálculos por cada trabalhador amostrado. Assim, foi determinada a carga de trabalho físico imposta pelas atividades relacionadas de forma a estabelecer os limites aceitáveis para um desempenho contínuo no trabalho, bem como ajustar a carga de trabalho físico à capacidade dos trabalhadores. A partir da frequência cardíaca, pode-se classificar a carga de trabalho, como descrito na Tabela 2.

Tabela 2. Classificação da atividade segundo frequência cardíaca média de trabalho.

Table 2. Activity classification according to average heart rate of work.

\begin{tabular}{lc}
\hline Carga Física de Trabalho & Frequência Cardíaca (em bpm) \\
\hline Muito Leve & $<75$ \\
Leve & $75-100$ \\
Moderadamente Pesada & $100-125$ \\
Pesada & $125-150$ \\
Muito Pesada & $>150$ \\
\hline
\end{tabular}

bpm - Batimentos cardíacos por minuto.

Fonte: Adaptado de Couto (2002).

\section{Avaliação biomecânica}

A avaliação biomecânica foi realizada através da análise tridimensional, utilizando a técnica de gravação em vídeo dos trabalhadores realizando as atividades. Os movimentos foram "congelados", para medição dos ângulos dos diversos segmentos corpóreos. As forças envolvidas foram medidas para aplicação do programa computacional de modelo biomecânico tridimensional de predição de posturas e forças estáticas (3DSSPP ${ }^{\mathrm{TM}}$ ), desenvolvido pela Universidade de Michigan, dos Estados Unidos (UNIVERSITY OF MICHIGAN, 2011).

Para a análise com o modelo tridimensional, foram fornecidos os ângulos das articulações, obtidos durante a realização das tarefas; o valor, a magnitude e a direção das forças aplicadas; o número de mãos utilizadas; e os dados antropométricos de altura e peso da população envolvida.

A força de compressão sobre a coluna vertebral, avaliada entre as vértebras Lombar 5 e Sacral 1 $\left(\mathrm{L}_{5}-\mathrm{S}_{1}\right)$ da mesma, foi comparada com o valor limite de $3.426,0 \mathrm{~N}$, que corresponde à força máxima capaz de ser suportada pela coluna vertebral sem a ocorrência de lesões.

Nas atividades onde havia manuseio de cargas, para a determinação dos esforços musculares e da análise biomecânica, os dados foram levantados por meio de medições diretas das forças envolvidas nas atividades com o uso de uma célula de carga da marca Kratos, modelo IDDK, com capacidade para até $1.000 \mathrm{~N}$.

\section{Avaliação do risco de lesão por esforços repetitivos/distúrbios osteomusculares relacionados ao trabalho (LER/DORT)}

A avaliação dos riscos de lesão por esforços repetitivos/distúrbios osteomusculares relacionados ao trabalho (LER/DORT) foi realizada de acordo com a metodologia de avaliação simplificada do fator biomecânico de risco para distúrbios músculo esquelético de membros superiores relacionados ao trabalho, proposta por Couto (2002). O instrumento é composto por 25 perguntas relacio- 
nadas às características do trabalho, sendo que para cada pergunta há uma combinação de respostas SIM ou NÃO, obtendo-se um escore. A classificação do risco de LER/DORT se dá de acordo com o total de pontos, sendo: acima de 22 pontos (baixíssimo risco); entre 19 e 22 (baixo risco); entre 15 e 18 (risco moderado); entre 11 e 14 (alto risco); abaixo de 11 pontos (altíssimo risco).

\section{Fatores ambientais no local de trabalho}

A avaliação da exposição ao ruído ocupacional foi realizada utilizando um medidor do nível equivalente de ruído ("audiodosímetro"), marca 01dB, modelo Wed007, nível de compensação A e em circuito de resposta lenta. O microfone foi instalado próximo ao ouvido dos trabalhadores, utilizando-se a metodologia da Norma de Higiene Ocupacional (NHO) $\mathrm{N}^{\circ} 01$ da FUNDACENTRO. Os valores obtidos foram confrontados com os limites máximos de exposição determinados pela Norma Regulamentadora (NR) No 15 - Atividades e Operações Insalubres, do Ministério do Trabalho e Emprego, em seu Anexo 1.

O ambiente térmico do local de trabalho foi avaliado por meio do uso do medidor de Índice de Bulbo Úmido e Termômetro de Globo - IBUTG modelo TGD 400. Os aparelhos foram posicionados no ambiente de trabalho, junto às atividades, e as leituras realizadas a cada 5 minutos durante, no mínimo, 120 minutos, conforme metodologia da NHO-06 da FUNDACENTRO. Os valores obtidos foram confrontados com os limites máximos de exposição determinados pela NR-15, Anexo 3.

Na avaliação da vibração foi utilizado um medidor marca $01 \mathrm{~dB}$, modelo Maestro, o qual possui um acelerômetro triaxial (direções $\mathrm{X}, \mathrm{Y}$ e Z) e um aparelho registrador dos valores de aceleração em $\mathrm{m} \mathrm{s}^{-2}$. O acelerômetro foi instalado nas mãos e dedos dos operadores. A avaliação foi realizada de acordo com a metodologia estabelecida nas Normas ISO 2631 e ISO/DIS 5349. Os resultados das medições foram comparados com os valores recomendados pela NHO-10 da FUNDACENTRO, expressos em aceleração resultante de exposição normalizada (Aren), bem como com os limites máximos de exposição determinados no Anexo 8 da NR-15.

Os dados de temperatura foram obtidos em todas as atividades e os níveis de ruído e vibração somente nas atividades de cubagem rigorosa de árvores e coleta de discos de madeira, as quais são desenvolvidas com utilização de motosserra.

\section{RESULTADOS E DISCUSSÃO}

\section{Avaliação da Carga de Trabalho Físico}

A partir do monitoramento das frequências cardíacas durante a realização de cada atividade foi calculada a carga cardiovascular (CCV), permitindo classificá-las segundo Couto (2002) e definidas as jornadas de trabalho recomendadas (Tabela 3).

Tabela 3. Carga cardiovascular (CCV), frequência cardíaca média (FCM), frequência cardíaca máxima (FCMax), classificação da atividade e jornada de trabalho recomendada para as atividades de mensuração florestal.

Table 3. Cardiovascular load (CCV), mean heart rate (FCM), classification of activity and work journey recommended for forest mensuration activities.

\begin{tabular}{|c|c|c|c|c|c|}
\hline Atividade & $\begin{array}{l}\text { CCV } \\
(\%)\end{array}$ & $\begin{array}{c}\text { FCM } \\
\text { (bpm) }\end{array}$ & $\begin{array}{c}\text { FCMax } \\
\text { (bpm) }\end{array}$ & $\begin{array}{l}\text { Classificação } \\
\text { da atividade }{ }^{1}\end{array}$ & $\begin{array}{c}\text { Jornada de trabalho } \\
\text { recomendada }^{2}\end{array}$ \\
\hline Levantamento de Campo para Inventário Florestal & 49 & 110 & 154 & Moderadamente Pesada & $49 / 11$ \\
\hline Levantamento de Sobrevivência & 53 & 109 & 145 & Moderadamente Pesada & $45 / 15$ \\
\hline Coleta de Solos & 57 & 124 & 166 & Moderadamente Pesada & $42 / 18$ \\
\hline Coleta de Discos de Madeira & 54 & 108 & 140 & Moderadamente Pesada & $45 / 15$ \\
\hline Cubagem Rigorosa de Árvores & 46 & 102 & 138 & Moderadamente Pesada & $52 / 08$ \\
\hline Determinação do Fator de Empilhamento & 41 & 99 & 136 & Leve & $60 / 00$ \\
\hline Inventário Físico de Madeira & 40 & 96 & 131 & Leve & $60 / 00$ \\
\hline Levantamento Residual Pós-Colheita & 56 & 105 & 131 & Moderadamente Pesada & $43 / 17$ \\
\hline
\end{tabular}

Na quase totalidade das atividades avaliadas, a CCV encontrada foi superior ao valor limite de $40 \%$ recomendado por Apud (1989). Apenas a atividade de inventário físico de madeira encontra-se dentro dos limites recomendados, sendo classificada como atividade leve. Por sua vez, a ativi- 
dade de determinação de fator de empilhamento, embora tenha apresentado CCV ligeiramente superior ao limite recomendado, seus ciclos de trabalho permitem classificá-la como leve, visto que a frequência cardíaca média durante toda a jornada de trabalho foi de $99 \mathrm{bpm}$.

De acordo com Seixas (1991), o trabalho realizado no setor florestal é considerado como uma das mais difíceis ocupações, sendo que, exceto os trabalhos em viveiros de produção de mudas, a maior parte das atividades florestais podem ser classificadas como moderadamente pesadas a pesadas. Destarte esse cenário, os conceitos de ergonomia e saúde ocupacional têm sido usualmente ignorados, de acordo com resultados encontrados por Fiedler et al. (2011). Apud et al. (1999) afirmam que sobrecargas mínimas, como a verificada na atividade de determinação do fator de empilhamento, são capazes de produzir enfermidades no organismo dos trabalhadores, levando a perdas de rendimento, afastamentos e até mesmo a invalidez permanente.

As frequências cardíacas máximas observadas ao longo da jornada de trabalho para todas as atividades avaliadas demonstraram que houve picos, deixando os trabalhadores expostos a sobrecargas que podem aumentar ainda mais os riscos à saúde. Couto (2002) afirma que, durante uma jornada de trabalho de oito horas, a frequência cardíaca não deve exceder a 110 bpm, pois os trabalhadores quando expostos a estas situações podem ter a integridade de sua saúde comprometida, ficando susceptíveis aos Distúrbios Osteomusculares Relacionados ao Trabalho - DORT, estresse, cansaço mental, problemas cardiovasculares dentre outras patologias. Ainda, de acordo com Katch e Mcardle (1996), o fluxo sanguíneo para o coração pode ser prejudicado durante a execução de atividades que requerem grande esforço cardiovascular, a ponto de ocorrer tonteira e vertigem, quando se reduz o fluxo sanguíneo para o cérebro, podendo dar origem à hipertensão arterial e ao acidente vascular cerebral.

Para as atividades analisadas, verificou-se que a grande maioria foi classificada como moderadamente pesadas, o que, de acordo com Couto (2002), pode favorecer o surgimento de lombalgias nos trabalhadores e causar afastamentos de até 10 dias, sendo frequentes as reincidências.

Face aos resultados encontrados, exceto para as atividades de determinação do fator de empilhamento e inventário físico de madeira, torna-se necessário a determinação de pausas para descanso para todas as demais atividades. A ausência das pausas nas atividades pesadas está relacionada ao acúmulo de ácido lático que resulta em fadiga, provocando cansaço, desmotivação, irritabilidade, redução das capacidades cognitivas e sintomas psicossomáticos (RIO; PIRES, 1999).

As pausas devem ser frequentes e menores, pois até certo limite, melhor será a recuperação do trabalhador e mais fácil a manutenção do ritmo de trabalho. Essas pausas devem ser adequadamente distribuídas durante a jornada de trabalho, pois elas representam um auxílio ao mecanismo fisiológico de compensação e recuperação do trabalhador, evitando a fadiga. Também não devem ser instituídas livremente pelos trabalhadores, pois podem se tornar menos eficiente que as programadas, em razão de poderem ter sido escolhidas em momentos inadequados (COUTO, 2002).

\section{Avaliação Biomecânica}

Para as atividades de levantamento de sobrevivência e inventário físico de madeira, não foi realizada a avaliação biomecânica, visto que as mesmas não envolvem manuseio e, ou, levantamento de cargas, posturas forçadas e nem uso de força. Para cada uma das demais atividades avaliadas, são apresentados os resultados das análises das forças aplicadas nas articulações e no disco $\mathrm{L}_{5}-\mathrm{S}_{1}$ da coluna vertebral dos trabalhadores, bem como os percentuais de capazes (indivíduos aptos) para cada uma das articulações analisadas (Tabela 4).

Com exceção das atividades de determinação do fator de empilhamento e cubagem rigorosa de árvores na etapa de abate das árvores, todas as demais apresentaram valores de força de compressão no disco $\mathrm{L}_{5}-\mathrm{S}_{1}$ da coluna vertebral abaixo do limite máximo recomendado pelo modelo 3DSSPP ${ }^{\mathrm{TM}}$, que é de 3.426,3 N, indicando ausência de risco de lesão nas articulações da coluna vertebral para os trabalhadores. Entretanto, as atividades de determinação do fator de empilhamento e cubagem rigorosa de árvores na etapa de abate das árvores, apresentaram, respectivamente, forças de compressão de 3.554 e $3.506 \mathrm{~N}$. Estes valores são decorrentes das particularidades das atividades, tais como posturas com o tronco inclinado e os braços esticados, o que, de acordo com Hall (2013), desloca o centro de gravidade do corpo e gera forças de compressão excessivas sobre o disco $\mathrm{L}_{5}-\mathrm{S}_{1}$. 
Tabela 4. Resultado da avaliação biomecânica para as atividades de mensuração florestal.

Table 4. Results of biomechanical analysis for forest mensuration activities.

\begin{tabular}{|c|c|c|c|c|c|c|}
\hline Atividade & $\begin{array}{l}\text { Postura } \\
\text { Típica }\end{array}$ & $\begin{array}{l}\text { Tempo na } \\
\text { postura } \\
(\%)\end{array}$ & $\begin{array}{c}\text { Força de } \\
\text { compressão no } \\
\text { disco L5-S1 (N) }\end{array}$ & $\begin{array}{c}\text { Condição } \\
\text { de suportar } \\
\text { a carga }\end{array}$ & Articulação & $\begin{array}{c}\text { Percentual de } \\
\text { capazes nas } \\
\text { articulações (\%) }\end{array}$ \\
\hline $\begin{array}{l}\text { Levantamento de } \\
\text { campo para inventário } \\
\text { florestal }\end{array}$ & & 68 & $1.228 \pm 73$ & SRL & $\begin{array}{c}\text { Punho } \\
\text { Cotovelo } \\
\text { Ombro } \\
\text { Tronco } \\
\text { Coxofemorais } \\
\text { Joelho } \\
\text { Tornozelo } \\
\end{array}$ & $\begin{array}{c}99 \\
100 \\
99 \\
99 \\
97 \\
99 \\
98 \\
\end{array}$ \\
\hline Coleta de solos & & 45 & $1.236 \pm 316$ & SRL & $\begin{array}{c}\text { Punho } \\
\text { Cotovelo } \\
\text { Ombro } \\
\text { Tronco } \\
\text { Coxofemorais } \\
\text { Joelho } \\
\text { Tornozelo }\end{array}$ & $\begin{array}{l}10 \\
23 \\
91 \\
87 \\
98 \\
88 \\
99\end{array}$ \\
\hline $\begin{array}{l}\text { Coleta de discos } \\
\text { de madeira }\end{array}$ & & 55 & $2.431 \pm 246$ & SRL & $\begin{array}{c}\text { Punho } \\
\text { Cotovelo } \\
\text { Ombro } \\
\text { Tronco } \\
\text { Coxofemorais } \\
\text { Joelho } \\
\text { Tornozelo } \\
\end{array}$ & $\begin{array}{l}99 \\
96 \\
96 \\
95 \\
82 \\
86 \\
88 \\
\end{array}$ \\
\hline $\begin{array}{lr}\text { Cubagem } & \text { rigorosa } \\
\text { de } & \text { árvores } \\
\text { (etapa de } & \text { abate } \\
\text { das árvores) } & \end{array}$ & & 39 & $3.554 \pm 259$ & CRL & $\begin{array}{c}\text { Punho } \\
\text { Cotovelo } \\
\text { Ombro } \\
\text { Tronco } \\
\text { Coxofemorais } \\
\text { Joelho } \\
\text { Tornozelo } \\
\end{array}$ & $\begin{array}{c}99 \\
100 \\
99 \\
96 \\
80 \\
88 \\
98 \\
\end{array}$ \\
\hline $\begin{array}{lr}\text { Cubagem } & \text { rigorosa } \\
\text { de } & \text { árvores } \\
\text { (etapa de } & \text { medição } \\
\text { dos fustes) } & \end{array}$ & & 43 & $2.597 \pm 201$ & SRL & $\begin{array}{c}\text { Punho } \\
\text { Cotovelo } \\
\text { Ombro } \\
\text { Tronco } \\
\text { Coxofemorais } \\
\text { Joelho } \\
\text { Tornozelo }\end{array}$ & $\begin{array}{c}99 \\
100 \\
99 \\
94 \\
81 \\
88 \\
91 \\
\end{array}$ \\
\hline $\begin{array}{l}\text { Determinação do fator } \\
\text { de empilhamento }\end{array}$ & & 73 & $3.506 \pm 271$ & CRL & $\begin{array}{c}\text { Punho } \\
\text { Cotovelo } \\
\text { Ombro } \\
\text { Tronco } \\
\text { Coxofemorais } \\
\text { Joelho } \\
\text { Tornozelo }\end{array}$ & $\begin{array}{c}99 \\
100 \\
99 \\
90 \\
70 \\
80 \\
97\end{array}$ \\
\hline $\begin{array}{l}\text { Levantamento residual } \\
\text { pós-colheita }\end{array}$ & & 52 & $1.666 \pm 145$ & SRL & $\begin{array}{c}\text { Punho } \\
\text { Cotovelo } \\
\text { Ombro } \\
\text { Tronco } \\
\text { Coxofemorais } \\
\text { Joelho } \\
\text { Tornozelo }\end{array}$ & $\begin{array}{c}99 \\
100 \\
99 \\
98 \\
85 \\
64 \\
14\end{array}$ \\
\hline
\end{tabular}

Obs.: SRL: postura sem risco de lesão nas articulações; CLR: postura com risco de lesão nas articulações.

Além da postura adotada pelos trabalhadores, outro aspecto que deve ser observado é o levantamento e transporte de cargas. De acordo com Silva et al. (2008), o levantamento de cargas pode causar sérios danos as articulações dos membros inferiores dos trabalhadores, visto que o peso levantado pode sobrecarregar as articulações do quadril, joelho e tornozelos, provocando desgaste articular, tendinites, lesão do menisco e ruptura dos ligamentos.

Ao se analisar os riscos de lesões nas articulações para as diferentes atividades avaliadas, verificou-se que a coleta de solos se destacou negativamente por apresentar altíssimo risco de lesões para os membros superiores, sendo que apenas $10 \%$ dos trabalhadores são capazes de exercer essa 
função sem risco de lesões para as articulações do punho e 23\% para as articulações do cotovelo. Outra atividade que merece destaque é o levantamento residual pós-colheita, o qual apresentou um percentual de capazes de $64 \%$ e $14 \%$ para as articulações do joelho e do tornozelo, respectivamente. Por fim, ambas as etapas da atividade de cubagem rigorosa de árvores apresentaram elevado risco de lesão as articulações coxofemorais, estando o percentual de capazes na ordem de $80 \%$.

A sobrecarga postural nos trabalhadores se caracteriza quando este se encontra fora da posição corporal neutra por um determinado período de tempo, favorecendo o surgimento de fadiga muscular, dores, inflamações e até lesões nos músculos e ligamentos dos membros inferiores (TORRES et al., 2014), chegando até mesmo a ocasionar a invalidez permanente para o trabalho.

Um dos causadores de tais distúrbios pode estar associado ao caráter repetitivo das tarefas, porém não é o único elemento a que se atribui essas disfunções musculoesqueléticas. Essas disfunções podem ter relações com a postura e com a força exigidas pelas tarefas e fatores ambientais, como a temperatura ambiente e os terrenos irregulares. Além disso, os aspectos mentais e psicológicos e relacionados à organização do trabalho podem também se associar a tais lesões (BOSCHMAN et al., 2012).

\section{Avaliação do Risco de LER/DORT}

Os resultados da avaliação do risco de desenvolvimento de LER/DORT para as atividades analisadas encontram-se na Tabela 5.

Tabela 5. Resultados da avaliação do risco de LER/DORT nas atividades de mensuração florestal.

Table 5. Results of the risk of RSI/MSDs in the forest mensuration activities.

\begin{tabular}{lcc}
\hline Atividade & Pontuação $^{1}$ & Risco de LER/DORT $^{\text {Baixo }}$ \\
\hline Levantamento de Campo para Inventário Florestal & 20 & Baixíssimo \\
Levantamento de Sobrevivência & 23 & Altíssimo \\
Coleta de Solos & 9 & Alto \\
Coleta de Discos de Madeira & 13 & Altíssimo \\
Cubagem Rigorosa de Árvores & 10 & Alto \\
Determinação do Fator de Empilhamento & 12 & Baixíssimo \\
Inventário Físico de Madeira & 23 & Moderado \\
Levantamento Residual Pós-Colheita & 17 & \\
\hline
\end{tabular}

' De acordo com a metodologia de avaliação simplificada do fator biomecânico no risco para distúrbios músculo esquelético de membros superiores relacionados ao trabalho, proposta por Couto (2002).

Observa-se que as atividades de mensuração florestal apresentam risco diferenciado para o desenvolvimento de LER/DORT, merecendo destaque as atividades de coleta de solos e cubagem rigorosa de árvores, que apresentaram risco altíssimo de desenvolvimento de LER/DORT (Tabela 5). Em seguida, a coleta de discos de madeira e a determinação do fator de empilhamento, ambas com alto risco de desenvolvimento de LER/DORT. As demais atividades apresentaram risco moderado a baixíssimo, indicando não serem potencialmente agressivas quanto a tais distúrbios.

O surgimento lento, principalmente nos membros superiores, de sintomas como dor, parestesia, sensação de peso e fadiga são as principais características da LER/DORT (PICOLOTO e SILVEIRA, 2008). As LER/DORT agrupam diferentes patologias, em diversos segmentos corporais, que estão diretamente relacionados com o movimento no trabalho e frequentemente são as causas de incapacidade laboral temporária ou permanente, como consequência da excessiva utilização das estruturas anatômicas do sistema musculoesquelético e da falta de tempo para recuperação.

O estudo de Negri et al. (2014) evidencia dois determinantes de risco para o desenvolvimento de LER/DORT: a organização e a ergonomia do trabalho; as quais envolvem características específicas do trabalho realizado em cada função, incluindo horários, pausas, duração da jornada, horários extremos, concepção da produção, complexidade, necessidade de habilidades e esforços, controle, relações interpessoais, perspectivas de carreira, estilo de gestão, características e cultura organizacional.

Simões et al. (2012), ao analisarem os fatores associados ao absenteísmo relacionado a doenças ocupacionais em uma empresa florestal, verificaram que a ocorrência de atestados médicos entre os trabalhadores pode ser atribuída às altas exigências físicas da atividade. Os autores apontam como fatores de sobrecarga para a atividade a realização de movimentos repetitivos com os membros superiores, o carregamento de peso, a postura inadequada, a vibração e organização do trabalho, muitas vezes, por tarefa. Os efeitos cumulativos da sobrecarga física têm se manifestado principalmente 
com agravos à saúde relacionados ao sistema osteomuscular. De fato, vários estudos têm apontado a presença de fatores de risco organizacionais e psicossociais condizentes com LER/DORT (CARMO et al., 2010; SANTOS; LIMA NETO, 2014; SILVA et al., 2013).

\section{Avaliação de Fatores Ambientais}

Durante o período de avaliação, foi encontrado um índice de bulbo úmido e termômetro de globo (IBUTG) igual a 36,7. Este valor, mesmo para as atividades classificadas como leves, deixa evidente a sobrecarga térmica e extrapola os limites legais, não sendo permitido o trabalho sem a adoção de medidas adequadas de controle.

O IBUTG funciona como um indicador, englobando os principais fatores causadores da sobrecarga térmica (alta temperatura, metabolismo, calor radiante e alta umidade relativa do ar), além dos principais agentes atenuadores da mesma (ventilação do ambiente, baixa umidade relativa do ar e baixa temperatura), estabelecendo o tempo de trabalho e repouso (COUTO, 2002). Segundo Fiedler et al. (2007), valores acima de $30^{\circ} \mathrm{C}$ potencializam riscos de lesões à saúde do trabalhador, a precisão do trabalho diminui com tendência de aumento dos acidentes. Sob condições inadequadas em relação a sobrecarga térmica, torna-se necessário reduzir o tempo de permanência do trabalhador no local de trabalho, devendo ser feito o rodízio de funções e o estabelecimento de pausas laborais para descanso e reidratação (COUTO, 2002). De fato, Lundgren et al. (2014), analisando o estresse causado pelo calor associado com a redução de produtividade, concluíram que valores altos de IBUTG tiveram significante impacto na produtividade, em todos os locais de trabalho.

Os valores obtidos para os níveis de ruído equivalente (Leq) nas atividades de cubagem rigorosa de árvores e coleta de discos de madeira foram de 91,7 e 89,3 dB(A), respectivamente, valores que se encontram acima dos limites legais para uma jornada de trabalho de 8 horas por dia. Para as demais atividades, os níveis de Leq ficaram abaixo dos limites legais, não representando risco ocupacional aos trabalhadores. Couto (2002) define o ruído como sendo um som ou complexo de sons que causam uma sensação de desconforto. A definição técnica de ruído é a de um estímulo auditivo que não contém informações úteis para a tarefa em execução. A sensação de desconforto afeta física e psicologicamente o ser humano, causando, dependendo dos níveis, lesões irreversíveis no aparelho auditivo do trabalhador, principalmente a surdez definitiva. Os problemas auditivos causados pelo ruído são determinados pelo nível de pressão sonora, frequência e tempo de exposição (LOPES et al., 2004; PMAC, 1994).

$\mathrm{Na}$ avaliação da vibração, os valores de aceleração resultante de exposição normalizada para vibração de mãos e braços encontrados foram, para as atividades de cubagem rigorosa de árvores e coleta de discos de madeira, respectivamente, 2,47 e 3,11 m/ $\mathrm{s}^{2}$ estando, portanto, abaixo do limite de exposição diária e não representando riscos à saúde e segurança dos trabalhadores. Considerando que a vibração é um importante agente de risco ocupacional, é desejável que sejam observados uma série de critérios no que tange às normas de uso das motosserras, pois respeitar os limites de uso diário e estabelecer períodos de pausa, bem como as condições de adequação para uso do equipamento (tempo de vida útil, frequência de manutenção), são medidas imprescindíveis para minimizar o aparecimento de lesões geradas em função da exposição à vibração.

\section{CONCLUSÕES}

Nas condições em que este estudo foi conduzido, pode-se concluir que:

O ambiente de trabalho estudado proporcionava uma série de riscos ergonômicos aos trabalhadores durante o desempenho de suas atividades, apresentando riscos de lesões músculo-esqueléticas e de acidentes, principalmente em função da necessidade de o trabalhador se deslocar em terrenos com declividade acentuada e obstáculos diversos, favorecendo o surgimento de dores musculares causadas por posturas forçadas e, ou, inadequadas ou ferimentos por quedas.

Todas as atividades avaliadas ultrapassaram a carga-limite recomendada em pelo menos uma fase do ciclo e, ou, em pelo menos uma das articulações estudadas, devido à adoção de posturas estáticas de flexão do tronco por longos períodos de tempo e movimentos repetitivos de flexão associada à rotação do tronco.

A análise biomecânica indicou a existência de risco significativo de lesão nas articulações da coluna vertebral para as atividades de cubagem rigorosa de árvores na fase de abate das árvores e 
determinação do fator de empilhamento; riscos estes decorrentes das características intrínsecas das atividades, exigindo posturas com o tronco inclinado e os braços esticados, gerando forças de compressão excessivas sobre o disco $\mathrm{L}_{5}-\mathrm{S}_{1}$ da coluna vertebral.

$\mathrm{Na}$ avaliação da carga de trabalho físico, apenas as atividades de determinação do fator de empilhamento e inventário físico de madeira encontram-se dentro dos limites de carga cardiovascular recomendados, não sendo, portanto, necessária qualquer alteração na organização do trabalho para essas atividades.

Todas as demais atividades apresentaram carga cardiovascular acima do limite recomendado, bem como elevadas frequências cardíacas médias, tendo sido classificadas como moderadamente pesadas, indicando a necessidade de reorganização do trabalho e adequação das cargas e posturas adotadas.

O fator ambiental ruído apresentou-se como risco para as atividades envolvendo a utilização de motosserra, sendo necessário a adoção de medidas para redução do ruído na fonte, ou a redução da transmissão do ruído, ou, em última instância, o fornecimento de proteção auditiva aos trabalhadores.

$\mathrm{O}$ fator ambiental vibração, nas atividades analisadas, não se apresentou como fonte de riscos ocupacionais para os trabalhadores. Entretanto, a sobrecarga térmica apresentou-se em desconformidade no período do estudo, sendo necessário a adoção de medidas organizacionais e de controle da exposição dos trabalhadores a este fator.

\section{REFERENCIAS BIBLIOGRÁFICAS}

ABRUZZI, R. C.; PIRES, M. R.; DEDAVID, B. A.; KALIL, S. B. Relação das propriedades mecânicas e densidade de postes de madeira de eucalipto com seu estado de deterioração. Revista Árvore, Viçosa, v. 36 n. 6, p. 1173$1181,2012$.

APUD, E. Guidelines on ergonomics study in forestry. Genebra: ILO, 1989. 241 p.

APUD, E.; GUTIÉRREZ, M.; LAGOS, S.; MAUREIRA, F.; MEYER, F.; ESPINOSA, J. Manual de Ergonomia Forestal. Concepción: Universidad de Concepción, 1999.

BOSCHMAN, J. S.; MOLEN, H. F. V. M.; SLUITER, J. K.; DRESEN M. H. W. F. Musculoskeletal disorders among construction workers: a one-year follow-up study. BioMed Central Musculoskeletal Disorders, v. 13, p. 196, 2012.

BRAZ, R. F.; OLIVEIRA, J. T. S.; ROSADO, A. M.; VIDAURRE, G. B.; PAES, J. B.; TOMAZELLO FILHO, M.; LOIOLA, P. L. Caracterização anatômica, física e química da madeira de clones de Eucalyptus cultivados em áreas sujeitas à ação de vento. Brazilian Journal of Wood Science, v. 5, n. 2, p. 127-137, 2014.

CARMO, M. C.; SOUZA, A. P.; MINETTE, L. J. Avaliação ergonômica da operação de aplicação de gel em duas empresas florestais. Revista Eletrônica Produção \& Engenharia, v. 3, n. 1, p. 210-223, 2010.

CORONA, P.; CHIRICI, G.; McROBERTS, R. E.; WINTER, S.; BARBATI, A. Contribution of large-scale forest inventories to biodiversity assessment and monitoring. Forest Ecology and Management, Amsterdam, v. 262, n. 11, p. 2061-2069, 2011.

COUTO, H. A. Ergonomia aplicada ao trabalho em 18 lições. Belo Horizonte: ERGO Editora, 2002. 202 p.

FIEDLER, N. C.; BARBOSA, R. P.; ANDREON, B. C.; GONÇALVES, S. B.; SILVA, E. N. Avaliação das posturas adotadas em operações florestais em áreas declivosas. Floresta e Ambiente, Seropédica, v. 18, n. 4, p. 402409. 2011.

FIEDLER, N. C.; SANTOS, A. D. L.; GATTO, A. C.; LOPES, E. S.; OLIVEIRA, J. D. S. Avaliação das condições do ambiente de trabalho em atividades de poda de árvores. Cerne, Lavras, v. 13, n. 1, p. 19-24, 2007.

FREITAS, A. G.; WICHERT, M. C. P. Comparação entre instrumentos tradicionais de medição de diâmetro 
e altura com o Criterion 400. Piracicaba: IPEF, 1998, 7 p. (Circular Técnica, 188).

HALL, S. Biomecânica básica. 6.ed. São Paulo: Guanabara Koogan, 2013. 450 p.

KATCH, F. I.; McARDLE, W. D. Nutrição, exercício e saúde. Rio de Janeiro: Medsi, 1996. 666 p.

LOPES, E. S.; ZANLOREZI, E.; COUTO, L. C.; MINETTI, L. J. Análise do ambiente de trabalho em indústrias de processamento de madeira na região Centro-Sul do Estado do Paraná. Scientia Forestalis, Piracicaba, n. 66, p. 183-190, 2004.

LUNDGREN, K.; KUKLANE, K.; VENUGOPAL, V. Occupational heat stress and associated productivity loss estimation using the PHS model (ISO 7933): a case study from workplaces in Chennai, India. Global Health Action, v. 7, n. 1, p. 25362, 2014.

MIGUEL, E. P.; CANZI, L. F.; RUFINO; R. F.; SANTOS, G. A. Ajuste de modelo volumétrico e desenvolvimento de fator de forma para plantios de Eucalyptus grandis localizados no Município de Rio Verde - GO. Enciclopédia Biosfera, Goiânia, v. 6, n. 11, p. 1-13, 2010.

MOHREN, G. M. J.; HASENAUER, H.; KÖHL, M.; NABUURS, G. J. Forest inventories for carbon change assessments. Current Opinion in Environmental Sustainability, v. 4, p. 686-695, 2012.

NEGRI, J. R.; CERVENY, G. C. O.; MONTEBELO, M. I. L.; TEODORI, R. M. Perfil sociodemográfico e ocupacional de trabalhadores com LER/DORT: estudo epidemiológico. Revista Baiana de Saúde Pública, Salvador, v. 38, n. 3, p. 555-570, 2014.

OJHA, P.; KWATRA, S. Role of ergonomics in reduction of occupational health hazards in forestry. Asian Journal of Home Science, v. 6, n. 2, p. 302-307, 2011.

PMAC. Exposição ao ruído: norma para a proteção de trabalhadores que trabalham em atividades com barulho. Proteção, v. 6, n. 29, p. 136-138, 1994.

RIO, R. P.; PIRES, L. Ergonomia: fundamentos da prática ergonômica. Belo Horizonte: Health, 1999. 200 p.

SANTOS, J. F.; LIMA NETO, J. S. Análise de prevalência de LER/DORT e sua influência na capacidade para o trabalho e na qualidade de vida de trabalhadores rurais. Cadernos de Educação, Saúde e Fisioterapia, v. 1, n. 1, p. 18-19, 2014.

SATO, L. Prevenção de agravos à saúde do trabalhador: replanejando o trabalho através das negociações cotidianas. Caderno de Saúde Pública, Rio de janeiro, v. 18, n. 5, p. 1147-66, 2002.

SEIXAS, F. Avaliação do esforço físico dispendido em operações florestais: um exemplo na operação de colheita de sementes. Série Técnica IPEF, Piracicaba, v. 7, n. 22, p. 1-16, 1991.

SILVA, E. P.; MINETTE, L. J. SOUZA, A. P.; MARÇAL, M. A.; SANCHES, A. L. P. Fatores organizacionais e psicossociais associados ao risco de LER/DORT em operadores de máquinas de colheita florestal. Revista Árvore, Viçosa, v. 37, n. 5, p. 889-895, 2013.

SILVA, E. P.; SOUZA, A. P.; MINETTE, L. J.; BAETA, F. C.; VIEIRA, H. A. N. F. Avaliação biomecânica do trabalho de extração manual de madeira em áreas acidentadas. Scientia Forestalis, Piracicaba, v. 36, n. 79, p. 231-235, 2008.

SIMÕES, M. R. L.; ROCHA, A. M.; SOUZA, C. Fatores associados ao absenteísmo-doença dos trabalhadores rurais de uma empresa florestal. Revista Latino-Americana de Enfermagem, v. 20, n. 4, p. 1-9, 2012. 
Schettino et al. - Avaliação ergonômica do processe de mensuração florestal

TONELLO, K. C.; DIAS, H. C. T.; SOUZA, A. L.; RIBEIRO, C. A. A. S.; LEITE, F. P. Morfometria da bacia hidrográfica da Cachoeira das Pombas, Guanhães - MG. Revista Árvore, Viçosa, v. 30, n. 5, p. 849-857, 2006.

TORRES, B. P. L.; MUÑOZ, E. L. G.; RODRIGUEZ, C. C.; LÓPEZ, E. O. Evaluación de sobrecarga postural en trabajadores: revisión de la literatura. Ciencia \& Trabajo, Santiago, v. 16, n. 50, p. 111-115, 2014.

UNIVERSITY OF MICHIGAN. 3D Static Strength Predicition Program ${ }^{\mathrm{TM}}$ - User's Manual. Michigan: University of Michigan, 2011. 108 p.

VAREKAMP, I.; VAN DIJK, F. J. H. Workplace problems and solutions for employees with chronic diseases. Occupational Medicine, v. 60, n. 4, p. 287-293, 2010.

VIBRANS, A. C.; SEVFNANI, L.; LINGNER, D. V.; GASPER, A. L.; SABBAGH, S. Inventário florístico florestal de Santa Catarina (IFFSC): aspectos metodológicos e operacionais. Pesquisa Florestal Brasileira, Colombo, v. 30, n. 64, p. 291-302, 2010.

Recebido em 25/09/2015

Aceito para publicação em 15/01/2016 